\title{
Investigating similarities and differences in individual reactions to the COVID-19 pandemic and the climate crisis
}

\author{
Nathaniel Geiger ${ }^{1}$ (D) Anagha Gore ${ }^{2} \cdot$ Claire V. Squire $^{2} \cdot$ Shahzeen Z. Attari ${ }^{2}$
}

Received: 8 December 2020 / Accepted: 10 June 2021/ Published online: 2 July 2021

(C) The Author(s), under exclusive licence to Springer Nature B.V. 2021

\begin{abstract}
How can individuals' responses to the coronavirus disease-19 (COVID-19) pandemic be used to inform constructive responses for climate action? We present an exploratory, mixed-methods investigation ( $N=1784$ US adults) into similarities and differences in individuals' reactions to COVID-19 and climate change in June 2020. Participants identified many similarities between the issues, indicating that both are harmful to public health, politically polarizing, have global impacts, and have solutions. Participants also perceived many differences between the two threats: many perceived COVID-19 as medical, natural, and on a shorter timescale, while many perceived climate change as environmental, human caused, and on a longer timescale. Emotional reactions to each topic predict topic-relevant behaviors, but more strongly, and with a broader range of emotional reactions, for climate change than COVID-19. Open-ended responses show that hope was elicited for both issues in response to contemplating taking collective and individual actions, and despair was elicited for both issues in response to perceiving that others do not take the issues seriously. Finally, participants perceived that they were engaging in relatively more COVID-19 mitigation behaviors and some climate change mitigation behaviors than others (i.e., the "better-than-average" effect). Many participants believed others were relatively unconcerned about both threats because of the invisibility of the threats, ignorance, and elite cues (e.g., then-President Trump downplaying the threat).
\end{abstract}

Keywords COVID-19 $\cdot$ Climate change $\cdot$ Cognitions $\cdot$ Emotions $\cdot$ Norms $\cdot$ Behavior

Nathaniel Geiger

nathgeig@indiana.edu

1 The Media School, Indiana University Bloomington, Franklin Hall, 601 E Kirkwood Ave, Bloomington, IN 47405, USA

2 O’Neill School of Public and Environmental Affairs, Indiana University Bloomington, 1315 East Tenth Street, Bloomington, IN 47405, USA 


\section{Introduction}

The coronavirus disease-19 (COVID-19) pandemic and global climate change are two major threats to society that require tradeoffs between short-term individual preferences and long-term collective well-being. Over 3.3 million people worldwide have died from COVID-19 as of May 2021 (Johns Hopkins COVID-19 Map 2021), with deaths pronounced in regions that did not prioritize measures to contain the virus and protect vulnerable populations. Similarly, negative impacts from climate change are projected to sharply increase if action is not taken to mitigate and adapt to the threat (IPCC 2019), with approximately 143 million people expected to be displaced as a result (Rigaud et al. 2018). Given commonalities in the global scale and severity of these two threats, examining individuals' response to COVID-19 may allow development of more effective methods of engaging the public with climate change (Bouman et al. 2021; Manzanedo and Manning 2020), as we examine here.

Converging cross-disciplinary research suggests a multidimensional approach to understanding individuals' reactions to risks (Doherty and Webler 2016; Singleton 2010; Slovic 1987; Tannenbaum et al. 2015). Here we consider reactions to COVID-19 and climate change along three interrelated dimensions: (1) threat perceptions, (2) emotional responses, and (3) normative perceptions.

\subsection{Threat perceptions}

We evaluate perceived similarities across the two issues. These can highlight potential "learning experiences": COVID-19-related experiences that could change individuals' perceptions of climate change (Manzanedo and Manning 2020). For example, individuals could note the shared need for international collective action (Balmford et al. 2020) or society's lack of advance threat preparation despite robust scientific evidence (Balmford et al. 2020; Kuzemko et al. 2020). Participants could also identify political polarization of both issues (Bergquist et al. 2020; Clinton et al. 2021), which in part reflects some individuals' mistrust in the scientific evidence and media coverage of the threats (McCright and Dunlap 2011; Oreskes and Conway 2011). The two issues also influence one another, and some may note that an unstable climate is a public health threat (e.g., see Maibach et al. 2021).

We also evaluate possible perceived differences across the two issues, which might be less helpful for climate change communication efforts. Some might note that political and societal responses to date have vastly differed across the two issues. Although both represent complex dynamic systems with lags between action and effect (a potential perceived similarity), individuals may note that relatively short lags with COVID-19 (weeks for community behavior changes) and relatively long for climate (decades for emissions reductions; Howarth et al. 2020). For example, individual-level behaviors such as social distancing and mask wearing are key in fighting COVID-19, whereas addressing climate change is more dependent on systemwide changes (Attari 2021). Many Americans view climate change as geographically and temporally distant (Miniard et al. 2020, but also see Brügger et al. 2021) and may view COVID-19 as more of a present problem than climate change. 


\subsection{Emotional reactions}

Emotional reactions to threats are increasingly recognized as key components of public responses to crises (Brosch 2021; Feldman and Hart 2016; Loewenstein et al. 2001; Lu and Schuldt 2015; Norgaard 2011; Roeser 2012; Slovic and Peters 2006). Here we consider six emotional reactions that have been identified in previous research as being particularly relevant to motivating or demotivating action across various domains: hope, despair, anxiety, anger, exhaustion, and boredom.

We focus most centrally on hope and despair, two future-oriented emotions that represent differential and sometimes overlapping emotional responses to future possibilities following traumatic experiences (Lazarus 1999) and existential threats (Pyszczynski et al. 2003). Hope is a positively valenced, approach-oriented emotion associated with a desired yet uncertain future goal (Lazarus 1999). Feeling hopeful can lower one's guard against disease contraction (Widmann 2020), but hope-inducing messages can be persuasive and motivational toward addressing health threats (Nabi 2015). Similarly, hope can promote climate action in many contexts (e.g., Bury et al. 2019; Geiger et al. 2021b; Ojala 2012; Smith and Leiserowitz 2014) but potentially discourage it in other contexts (e.g., Hornsey and Fielding 2016; also see van Zomeren et al. 2019). Conversely, despair is a negatively valenced, avoidance-oriented emotion reflecting perceptions of hopelessness and helplessness and is associated with frequent rumination (Copeland et al. 2020). During previous pandemics (i.e., SARS, MERS), many in affected regions experienced despair (and related emotions) during and after the outbreaks (Qian et al. 2005; Yoon et al. 2016). Similarly, learning about or experiencing the effects of climate change can stimulate despair in some (Albrecht 2011; Clayton et al. 2017; Moser 2007; Taylor 2020). Preliminary work suggests that despair (and related affective states) could potentially lead to long-term disengagement with issues such as climate change (Hmielowski et al. 2019; Landry et al. 2018; Salomon et al. 2017).

We also consider how anxiety, anger, boredom, and exhaustion predict responses to COVID-19 and climate change. Anxiety is a common reaction to both threats (Taylor 2020; Wang et al. 2020). Anxiety corresponds with uncertainty about future outcomes and promotes a focus on possible aversive outcomes. Anxiety exerts inconsistent motivational effects: in many cases, anxiety (or fear) can alert individuals to health and environmental threats, thus promoting action and information seeking (Tannenbaum et al. 2015; van Zomeren et al. 2010), but it can alternatively promote psychological avoidance and defensiveness (Kim and Niederdeppe 2013; O'Neill and Nicholson-Cole 2009; Stanley et al. 2021). Anger is an approach-oriented emotion that arises in response to perceived injustice (Van Doorn et al. 2014), and can either facilitate cooperation and motivate pro-social action toward societal threats (such as when it is directed toward those seen as culpable for causing climate change; Jones and Davison 2021; Kleres and Wettergren 2017; Stanley et al. 2021) or can be associated with anti-social or aggressive action (such as when individuals experience reactance toward perceived freedom threats of public health recommendations; Dillard and Peck 2000). Feeling exhausted or bored in response to threats (e.g., "COVID fatigue") might be associated with disengagement (a lack of action; e.g., Geiger et al. 2021b) as individuals lose motivation due to fatigue or a lack of psychological meaning associated with behaviors (Markowitz et al. 2013; Westgate and Wilson 2018).

Here we examine and compare emotional reactions to COVID-19 and climate change and how they can motivate action across the two threats. 


\subsection{Normative perceptions}

A third dimension guiding threat responses involves individuals' perceptions of others' reactions. Decades of social psychological research show that when dealing with novel threats, social cues provide valuable and trusted information regarding the extent to which a threat should be taken seriously (Cialdini and Goldstein 2004). However, individuals commonly misperceive others' behaviors, falsely perceiving that their own behavior is different from average (Miller and Prentice 1994). Although numerous factors influence these misconceptions, some work suggests that individuals may succumb to the better-than-average bias on pro-environmental behaviors, with most people perceiving that they engage in more proenvironmental behavior than the average person (Leviston and Uren 2020). This tendency can be problematic for encouraging pro-social behaviors because individuals adjust their opinions and behaviors to match their perceptions of others (Ajzen 1991; Goldberg et al. 2020); thus, if individuals perceive they are engaging in greater pro-social action than others, they may reduce their socially constructive behavior to better match the perceived norm (Schultz et al. 2007). Similarly, some have speculated that COVID-19 mitigation behaviors may be strongly influenced by perceptions of the extent to which others engage in such behaviors (Jetten et al. 2020).

There is reason to believe that most individuals might perceive that they are engaging in more socially responsible actions than others on both COVID-19 and climate change. Although compliance with health recommendations have been far from universal, most Americans self-report having extensively adjusted their behavior to contain the spread of COVID-19 (Czeisler et al. 2020). However, some COVID-19 mitigation behaviors, such as remaining at home, result in those engaging being invisible to others, while those who refuse to take such actions are highly visible to others (Jetten et al. 2020). Because of this visibility gap, many may underestimate the sacrifices that others are making to address COVID-19. Similarly, research shows that individuals underestimate others' concern about climate change (Leviston et al. 2013; Mildenberger and Tingley 2017) and underestimate others' engagement in green behaviors relative to their own (Leviston and Uren 2020). Here we extend previous work by examining individuals' comparison of their behaviors to others on several COVID-19 and climate mitigation behaviors.

\section{Present research}

The present work uses mixed-methods analysis of online survey responses to explore the dimensions considered above.

\section{Methods}

\subsection{Participants and procedure}

A sample of US adults $(N=1900)$ was recruited online via Amazon's Mechanical Turk (MTurk) in June 2020 and were compensated $\$ 3.00$ to $\$ 3.30$ for participation ${ }^{1}$. Participants

\footnotetext{
${ }^{1}$ Payment was increased midway through the study because survey completion took longer than estimated.
} 
who failed both of two attention checks described in Supplemental Materials ( $n=116,6 \%$ of sample) were excluded from analyses (final $N=1784$ ).

Overall, our sample was not representative of the US public but exhibited substantial diversity in various socio-demographic measures. Median sample age was 34 years, slightly younger than the median age of the US population of 38.2 years in 2018 (including minors; US Census Bureau 2019). Forty percent of participants identified as female (50.8\% in the US), $60 \%$ as male, and less than $1 \%$ as "other." Median household income from the previous year (2019) was between $\$ 40,000$ and 80,000 ( $\$ 60,226$ in the USA). Fifty-nine percent of participants identified as white non-Hispanic, with $13 \%$ identifying as white Hispanic and $13 \%$ as nonwhite Hispanic, 22\% as black/African American, 4\% as Asian, 2\% as American Indian or Alaska native, and less than $1 \%$ as Native Hawaiian or Pacific Islander (participants could select more than one ethnicity). Over $99 \%$ of participants held high school diplomas or GEDs, and $82 \%$ of participants held a college degree. Thirty-four percent of participants selfidentified as very liberal/liberal, $39 \%$ as moderate/slightly liberal/slightly conservative, and $27 \%$ as very conservative/conservative. As shown in Figure S1 (see Supplemental Materials), participants came from all 50 US states and DC. In summary, our sample overrepresents younger adults and the highly educated, yet has sufficient heterogeneity for an initial investigation into key questions.

\subsection{Measures}

The full survey is available in Supplemental Materials.

\subsubsection{Threat perceptions}

Participants wrote descriptions of their perceptions of similarities and differences between COVID-19 and climate change, inspired by Attari et al.' (2014) work. For each topic, participants then self-categorized into one of six categories reflecting their concern about the topic (based on Swim and Geiger 2017; modified slightly to create parallel wording for COVID-19). Participants completed two blocks of questions presented in random order, with within-block statement order also randomized. In one block, participants indicated their agreement with 29 statements about COVID-19, and in the other, their agreement with a parallel set of 29 statements about climate change (both on -2 to +2 Likert scales; see statements in Table 1). Statements reflected parallel themes across the two topics that we observed through prevailing media narratives and personal conversations.

Participants next indicated their agreement with nine statements related to immediate climate action preferences on -2 to +2 Likert scales. Five statements suggested preferences for avoiding immediate climate action: "we need to focus on the immediate problem of the economy before we take action on climate change," "we need to focus on the immediate problem of racial inequality before we take action on climate change," "we should not prioritize dealing with climate change because there are more pressing issues to deal with," "we should wait until the Coronavirus outbreak is under control before we take action on climate change," and "society and the world need time to heal and recover before tackling the next big issue." The other four statements indicated preferences for immediate climate action: "we need to address climate change, racial inequality, and the Coronavirus outbreak simultaneously," "given the societal impacts of the Coronavirus outbreak, I feel motivated to tackle other big problems like climate change," "some of the lessons we have learned from dealing 
Table 1 List of parallel pairs of survey items

1. Countries are coming together to eliminate the Coronavirus outbreak [climate change].

2. The Coronavirus outbreak [climate change] has caused communities to be in competition for shared resources.

3. Seeing others take action on the Coronavirus outbreak [climate change] encourages me to take action.

4. The Coronavirus outbreak [climate change] has shown that individuals need to come together collectively to address big societal problems.

5. Individuals will need to change their behavior if we want to address the Coronavirus outbreak [climate change].

6. Addressing the Coronavirus outbreak [climate change] will require action on a global scale.

7. Learning about the Coronavirus outbreak [climate change] has made me realize the importance of acting early on other global problems.

8. The Coronavirus outbreak [climate change] has shown that an authoritarian government is critical to addressing social problems.

9. Governments should help victims of the Coronavirus outbreak [climate change].

10. I feel a moral obligation to take action on the Coronavirus outbreak [climate change].

11. The Coronavirus outbreak [climate change] has exposed many injustices in society.

12. Addressing the Coronavirus outbreak [climate change] will require countries to work together toward a common goal.

13. We cannot address the Coronavirus outbreak [climate change] without international cooperation.

14. The U.S. is doing a good job of working with other countries on the Coronavirus outbreak [climate change].

15. I tend to seek out news about the Coronavirus outbreak [climate change].

16. I have the energy to act on the Coronavirus outbreak [climate change].

17. We should not take any actions to address the Coronavirus outbreak [climate change] that will hurt the economy.

18. I am concerned about the effects of the Coronavirus outbreak [climate change] on me personally.

19. I am concerned about the effects of the Coronavirus outbreak [climate change] on my family.

20. I am concerned about the effects of the Coronavirus outbreak [climate change] on my friends.

21. I am concerned about the effects of the Coronavirus outbreak [climate change] on my community.

22. I am concerned about the effects of the Coronavirus outbreak [climate change] on my country.

23. I am concerned about the effects of the Coronavirus outbreak [climate change] on people around the world.

24. I am concerned about the effects of the Coronavirus outbreak [climate change] on future generations.

25. Scientists do not know a lot about the Coronavirus outbreak [climate change].

26. I do not know a lot about the Coronavirus outbreak [climate change].

27. The Coronavirus outbreak [climate change] is worse than people thought it would be.

28. People are overreacting to the Coronavirus outbreak [climate change].

29. The Coronavirus outbreak [climate change] is under control now.

with the Coronavirus outbreak can be applied to addressing climate change," and "the Coronavirus outbreak has demonstrated our lack of preparation for global problems like climate change."

\subsubsection{Emotional reactions}

Participants indicated the extent to which they felt hope, despair, boredom, anxiety, exhaustion, and anger ${ }^{2}$ when considering (a) COVID-19 and (b) climate change on 0 "not at all" to 4 "very" scales. Participants then wrote about what makes them feel (i) hope and (ii) despair about (a) COVID-19 and (b) climate change.

\subsubsection{Normative perceptions and self-reported behavior}

Participants provided a written description of why some others do not perceive (a) COVID-19 and (b) climate change to be a serious threat. Next, participants self-reported their own

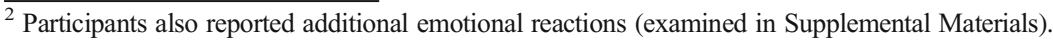


behaviors and perceptions of behaviors of others in their community over the past month on 0 "never" to 4 "all the time" scales. We assessed three COVID-19 preventative behaviors: (1) mask wearing in public, (2) avoiding socializing, and (3) staying 6 feet from others, and three climate action behaviors: (1) eating a climate-friendly diet, (2) reducing home energy usage, and (3) political climate action.

\subsubsection{Behavioral intentions}

Participants indicated their intentions to engage in the three above COVID-19 behaviors $(\alpha=$ .76) and climate behaviors $(\alpha=.70)$ over the next 3 months on the same scale as above.

\subsubsection{Conservatism of media consumption}

Participants self-assessed the political bent of their news sources on a 7-point scale from "very liberal" to "very conservative" (see Swim et al. 2019).

\section{Results}

\subsection{Threat perceptions}

Figure 1 shows participants' self-categorization on COVID-19 and climate change. Selfcategorization on climate change is fairly similar to nationally representative data collected in April 2020 (Leiserowitz et al. 2020). As can be seen in the figure, more participants selfcategorize as Alarmed about COVID-19 than climate change.

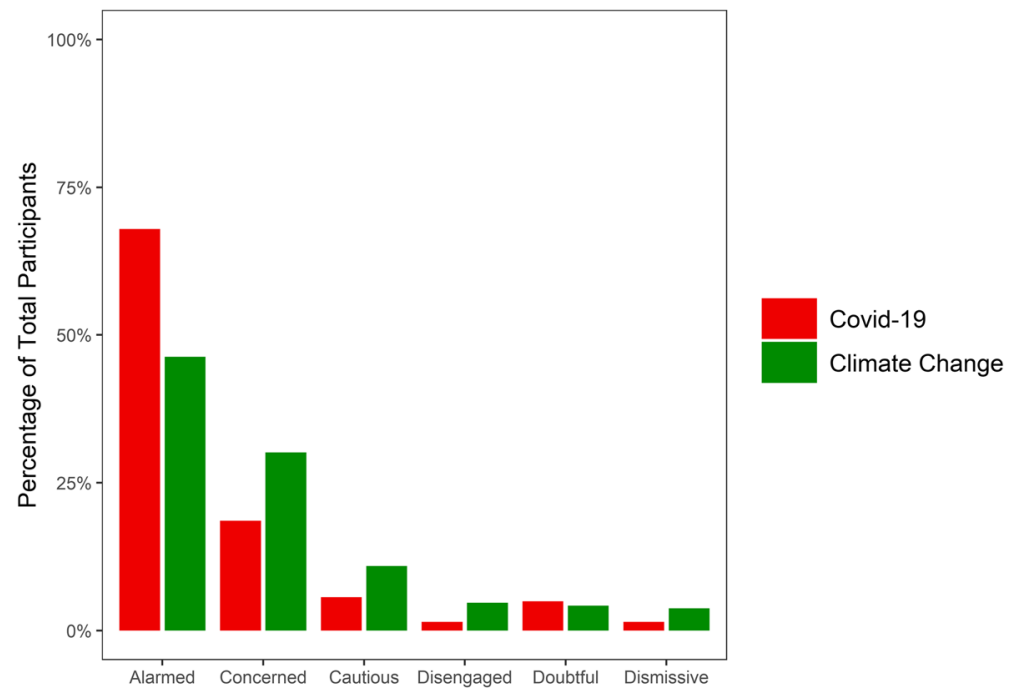

Figure 1 Self-categorization into COVID-19 and climate change concern categories. Categories further to the left represent stronger concern and greater awareness of the issue. Created using ggplot 2 package (Wickham et al. 2016) in R (R Core Team 2020) 
Next, we analyzed written descriptions of similarities and differences between the two issues. One coder went through to create the original code sheet (37 to 39 unique codes) and coded the first three ideas in each response. Two coders analyzed unclear responses together. Table 2 highlights the top 15 responses for similarities and differences (See Supplemental Text for other responses).

Table 2 shows that participants perceived many similarities between COVID-19 and climate change: many participants perceived both issues to be harmful to public health, politically polarizing, have global effects, are human caused, and to have solutions. Some participants highlighted the need for collective action or that climate change could exacerbate COVID-19. Some participants' copy-pasted responses from the web instead of writing a response.

Table 2 also shows perceived differences between the two topics. Many perceived the issues to fall into different domains, perceiving COVID-19 as a medical issue and climate change as an environmental issue. Related to this perceived distinction, some participants believed COVID-19 to be naturally occurring and climate change to be human caused. Many responses related to the time horizon of both threats, reflecting perceptions of COVID-19 as a short-term problem, happening now, and with immediate impacts and short-term solutions, in contrast to climate change as a long-term problem, gradually built, and with long-term impacts and long-term solutions.

Figure 2 shows that most expressed greater agreement with statements supporting the need for immediate climate action than they did with statements suggesting not taking immediate climate action. For example, participants tended to express greater agreement with the notion

Table 2 Perceived similarities and differences across issues

Similarities

What do you think are the similarities between the coronavirus outbreak and climate change?
Differences

What do you think are the differences between the coronavirus outbreak and climate change?

\begin{tabular}{|c|c|c|c|}
\hline Copied and pasted from the web & $24 \%$ & Copied and pasted from the web & $24 \%$ \\
\hline Harmful to public health & $18 \%$ & $\begin{array}{l}\text { Medical issue vs environmental } \\
\text { issue }\end{array}$ & $15 \%$ \\
\hline Nonsensical response & $14 \%$ & Nonsensical response & $14 \%$ \\
\hline Polarizing issue & $11 \%$ & Vague response & $8 \%$ \\
\hline Global effects & $9 \%$ & Immediate impact vs gradual impact & $8 \%$ \\
\hline Human caused & $6 \%$ & Natural vs manmade & $6 \%$ \\
\hline Both have solutions & $5 \%$ & $\begin{array}{l}\text { Short-term problem vs long-term } \\
\text { problem }\end{array}$ & $5 \%$ \\
\hline No similarities & $5 \%$ & Issue now vs issue in future & $4 \%$ \\
\hline They affect each other & $4 \%$ & Virus vs not a virus & $4 \%$ \\
\hline Worsened by human lifestyle & $4 \%$ & Different eradication measures & $4 \%$ \\
\hline Collective action needed & $3 \%$ & Fast vs slow & $3 \%$ \\
\hline $\begin{array}{l}\text { Climate affects weather affects outbreak, and seasons affect } \\
\text { outbreak }\end{array}$ & $3 \%$ & $\begin{array}{l}\text { Short-term solution vs long-term } \\
\text { solution }\end{array}$ & $3 \%$ \\
\hline $\begin{array}{l}\text { People ignore the problem, are disengaged, and do not want } \\
\text { to act }\end{array}$ & $3 \%$ & Kills vs does not kill & $3 \%$ \\
\hline Headed on wrong path and need action now & $3 \%$ & Visible threat vs invisible threat & $3 \%$ \\
\hline Unpredictable outcomes & $3 \%$ & Recent problem vs problem for years & $3 \%$ \\
\hline
\end{tabular}

For differences, COVID-19 responses are mentioned first followed by climate responses. Responses in italics represent less relevant themes 
that the two issues could be addressed simultaneously relative to the notion that climate change action should not be taken until after COVID-19 was addressed.

Next, we examined correlations for responses to each pair of parallel items that participants had completed for both COVID-19 and climate change, depicted in Figure 3. All item pairs were positively correlated with one another, yet the magnitudes of correlation drastically differed across different item pairs. On the most related end, the item pairs regarding endorsement of authoritarianism as a solution to each threat were very strongly correlated. Similarly, item pairs reflecting perceptions of (a) the extent to which the USA was cooperating internally, (b) participants' own knowledge, and (c) scientists' knowledge for each threat were strongly correlated between the two threats. Finally, item pairs related to mistrust, including perceptions that (a) others were overreacting to the threats, (b) the issues were under control, and (c) that actions to address the issues shouldn't hurt the economy, were strongly correlated between the two threats. On the least related end, item pairs reflecting perceptions that threats revealed competition between communities and concern about how each problem would affect various others were only moderately correlated, suggesting a distinction between how individuals perceived these components of the two topics.

\subsection{Emotional reactions}

Following Smith and Leiserowitz's (2014) work examining links between emotions and climate policy support, we used multiple regression examine the how each emotional appraisal uniquely predicts topic-relevant behavioral intentions. In Table 3, we regressed climate action intentions onto emotion reactions to climate change, and in a parallel regression, we regressed COVID-19 action intentions onto emotional reactions to COVID-19. In both, we control for media conservatism. See Tables S1 and S2 in Supplemental Materials for zero-order correlations and supplemental analyses.

All six emotional reactions predicted climate action intentions, while COVID-19 action intentions were predicted by despair, anxiety, and (negatively) boredom, but not hope, exhaustion, or anger. Overall, emotional reactions were much stronger predictors of intentions to act on climate (30\% variance explained) than COVID-19 (8\% variance explained).

As shown in Table 4, a variety of topics fostered hope about COVID-19. In particular, scientific advances and the possibility of a medical solution made many participants hopeful, as did contemplating an end to the outbreak. Collective and individual actions and efficacy also made many participants feel hopeful. A relatively small number of participants indicated not feeling hopeful regarding the topic.

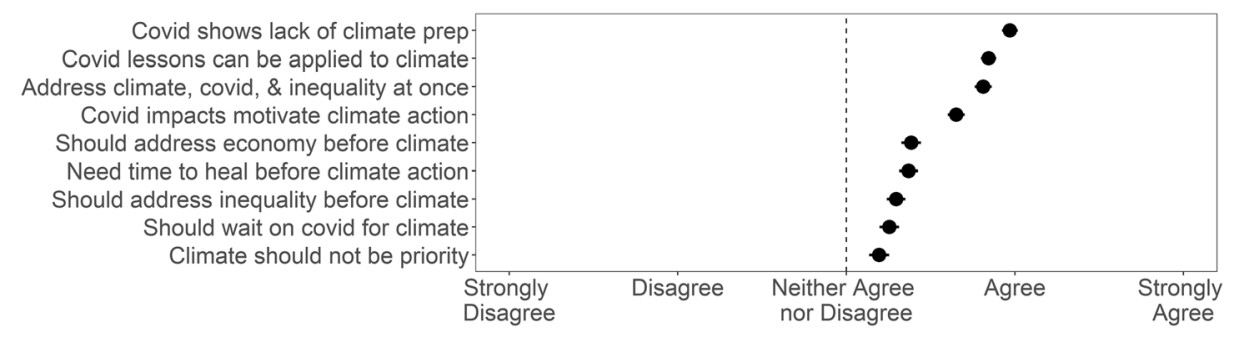

Figure 2 Means and 95\% confidence intervals for perceived connections between COVID-19 and other issues. Responses are arranged from greatest to least agreement 


Variable Name
Authoritarian govt. needed for crisis
Crisis is under control
US is cooperating internationally
People are overreacting
We shouldn't hurt economy
I don't know much about crisis
Crisis taught me about early action
Scientists don't know much about crisis
Behavior change needed
Crisis exposed injustices
Others motivate me
Collective action needed
Global action needed
I feel moral obligation to act
Concern about global ppl
Crisis worse than thought
International coop. required
I have energy to act
Government should help victims
International coop. is happening
Concern about self
Need international coop.
Concern about country
Concern about community
I seek out news
Concern about friends
Concern about family
Concern about future gens
Communities in competition

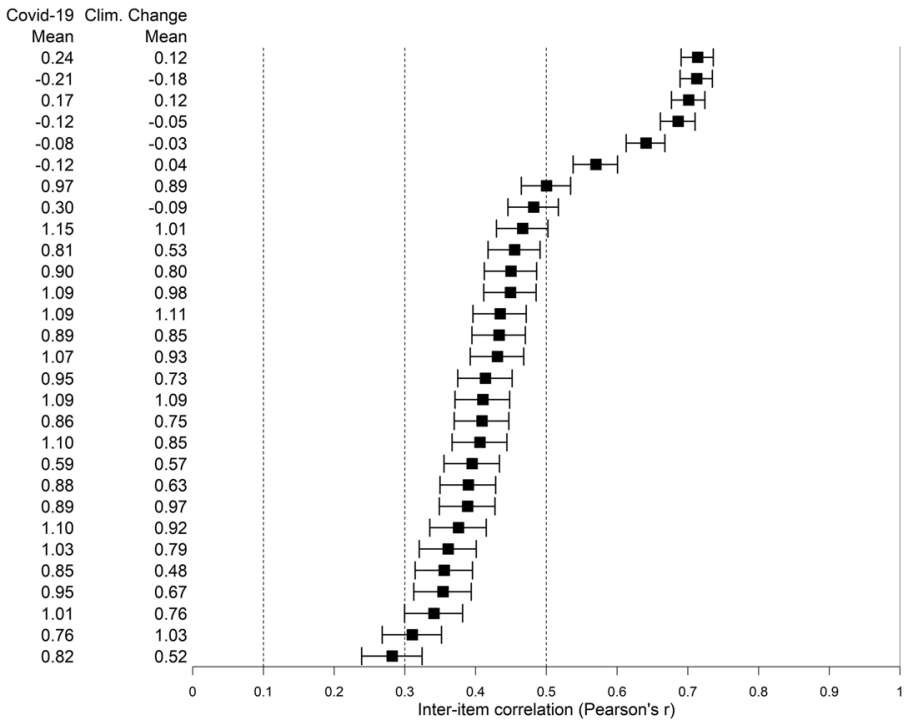

Figure 3 Point estimates and 95\% confidence intervals for inter-item correlations between responses to parallel items about COVID-19 and climate change. Items are arranged from strongest to weakest correlations. Dashed vertical lines represent cutoffs for small $(r=.1)$, medium $(r=.3)$, and large $(r=.5)$ correlations as defined by Cohen (1988). Clim., climate. Created using the forestplot package (Gordon et al. 2019) in R.

Table 4 also showed that responses were relatively similar for climate change: as with COVID-19, many participants (albeit a smaller percentage) reported feeling hopeful due to possible future science and technology to address the issue. Collective and individual actions and efficacy also emerged as a source of hope for climate change. Unlike with COVID-19,

Table 3 Emotional reactions to each risk predicting topic-relevant action intentions

\begin{tabular}{|c|c|c|}
\hline \multirow[t]{2}{*}{ Emotional reaction } & \multicolumn{2}{|l|}{ Topic of intended action } \\
\hline & Climate change $(95 \% \mathrm{CI})$ & COVID-19 $(95 \% \mathrm{CI})$ \\
\hline Hope & $\begin{array}{l}0.31 * * * \\
(0.27,0.35)\end{array}$ & $\begin{array}{l}0.03 \\
(-0.01,0.07)\end{array}$ \\
\hline Despair & $\begin{array}{l}0.15 * * * \\
(0.11,0.20)\end{array}$ & $\begin{array}{l}0.06 * * \\
(0.02,0.11)\end{array}$ \\
\hline Anger & $\begin{array}{l}0.12 * * * \\
(0.07,0.16)\end{array}$ & $\begin{array}{l}-0.02 \\
(-0.06,0.02)\end{array}$ \\
\hline Exhaustion & $\begin{array}{l}0.09 * * * \\
(0.05,0.14)\end{array}$ & $\begin{array}{l}-0.02 \\
(-0.07,0.03)\end{array}$ \\
\hline Boredom & $\begin{array}{l}-0.08 * * * \\
(-0.12,-0.04)\end{array}$ & $\begin{array}{l}-0.19 * * * \\
(-0.22,-0.15)\end{array}$ \\
\hline Anxiety & $\begin{array}{l}0.21 * * * \\
(0.16,0.25)\end{array}$ & $\begin{array}{l}0.14 * * * \\
(0.09,0.18)\end{array}$ \\
\hline Media conservatism & $\begin{array}{l}0.03 \\
(-0.002,0.06)\end{array}$ & $\begin{array}{l}-0.04 * \\
(-0.07,-0.01)\end{array}$ \\
\hline Constant (model intercept) & $\begin{array}{l}0.25^{* *} \\
(0.08,0.41)\end{array}$ & $\begin{array}{l}3.02 * * * \\
(2.83,3.21)\end{array}$ \\
\hline $\mathrm{R}^{2}$ & 0.30 & 0.08 \\
\hline F statistic $(\mathrm{df}=7 ; 1776)$ & $111.00 * * *$ & $21.50 * * *$ \\
\hline
\end{tabular}

Created using the stargazer package (Hlavac 2018). All VIFs $<2$. **p $<.01$, ***p $<.001$ 
Table 4 Participants' descriptions of elicitors of hope regarding each threat

COVID-19

In a few sentences, describe what makes you feel hopeful (if at all) about the Coronavirus outbreak.
Climate change

In a few sentences, describe what makes you feel hopeful (if at all) about climate change.
Copied and pasted from the web

Medical solution

The outbreak will end

Nonsensical response

Collective action

I don't feel hopeful

Scientists and research

People taking precautions

Decreasing mortality and numbers

World learned a good lesson from Covid-19

We are capable of tackling it

Vague response

It exposed other issues

Spending time with family

Government response

\begin{tabular}{lll}
$22 \%$ & Copied and pasted from the web & $21 \%$ \\
$18 \%$ & Nonsensical response & $19 \%$ \\
$13 \%$ & Growing awareness & $8 \%$ \\
$13 \%$ & Increasing eco-friendly innovation and technology & $8 \%$ \\
$9 \%$ & I don't feel hopeful & $8 \%$ \\
$7 \%$ & Collective action & $7 \%$ \\
$7 \%$ & We are capable of tackling it & $7 \%$ \\
$7 \%$ & Individual action & $7 \%$ \\
$5 \%$ & Government action & $5 \%$ \\
$5 \%$ & It is exaggerated or fake & $4 \%$ \\
$3 \%$ & Younger generations & $4 \%$ \\
$2 \%$ & Vague response & $4 \%$ \\
$2 \%$ & Pandemic impacts on nature and human thinking & $3 \%$ \\
$2 \%$ & Scientists and research & $3 \%$ \\
$2 \%$ & Ongoing action and initiatives & $3 \%$ \\
\hline
\end{tabular}

Responses in italics represent less relevant themes

some participants reported feeling hopeful based on a perception that climate change is exaggerated.

As shown in Table 5, there were both similarities and differences in sources of despair for COVID-19 and climate change. Two key themes emerged for both topics: incompetent government response and the perception that others were not taking the issue seriously. In contrast, more participants reported feeling no despair about climate change than regarding COVID-19, and a small number of people stated that other people's belief in climate change resulted in their feelings of despair. The direct health and economic consequences of COVID-

Table 5 Participants' descriptions of elicitors of despair regarding each of the two threats

COVID-19

In a few sentences, describe what makes you feel In a few sentences, describe what makes you feel despair (if at despair (if at all) about the Coronavirus outbreak. all) about climate change.

\begin{tabular}{llll}
\hline Copied and pasted from the web & $22 \%$ & Copied and pasted from the web & $21 \%$ \\
Nonsensical response & $14 \%$ & Nonsensical response & $16 \%$ \\
Loss of life and suffering & $13 \%$ & I don't feel despair & $9 \%$ \\
People not taking it seriously & $11 \%$ & Lack of government action and rollbacks & $9 \%$ \\
Job insecurity and economic downturn & $10 \%$ & Unaware and apathetic people & $8 \%$ \\
Pandemic worsening & $8 \%$ & People don't believe it exists & $6 \%$ \\
Trump and government response & $8 \%$ & Consequences & $6 \%$ \\
I don't feel despair & $6 \%$ & Vague response & $5 \%$ \\
Loss of faith in humanity & $5 \%$ & Could have acted sooner and may be too late now & $5 \%$ \\
Never-ending & $4 \%$ & Insufficient action & $4 \%$ \\
Waiting for a vaccine & $3 \%$ & Future impacts & $4 \%$ \\
Fear of self or loved one getting sick & $3 \%$ & Impact on flora and fauna & $3 \%$ \\
Vague response & $3 \%$ & People believe it exists/exaggerating its impacts & $3 \%$ \\
Loneliness/ mental health & $3 \%$ & Corporate power & $3 \%$ \\
Lockdown & $2 \%$ & People valuing economy over human life and planet & $3 \%$ \\
\hline
\end{tabular}

Responses in italics represent less relevant themes 
19 emerged as key themes inciting despair. A relatively small percentage of participants cited poor mental health as a source of despair.

\subsection{Normative perceptions}

Table 6 shows codes for why participants believe that others do not regard COVID-19 and climate change as serious threats (shown in Table 6). Many participants reasoned that others did not believe COVID-19 was serious because it seemed "invisible" (i.e., many others had not personally experienced or witnessed an infection), elite cues (e.g., then-President Trump downplaying the threat), or ignorance. Other participants explained that others downplay the threat because they were uninformed about the science, mistakenly perceived COVID-19 to be comparable to the flu, or perceived low mortality rates and a strong possibility of recovery. Additionally, some participants noted politicization of the topic and lack of trust in media and government as potential causes of others' lack of caution.

Participants' reasoning for why others did not take climate change seriously echoed many similar themes to COVID-19. Specifically, many participants reasoned that the perceived invisibility of climate change and lack of information explained others' lack of concern about the issue. Also, participants attributed some blame to inaccurate information provided by the government and then-President Trump, politicization, and lack of trust in media and scientific authorities. In contrast, with climate change, some emphasized monetary interests and propaganda spread by powerful interest groups (e.g., fossil fuel companies) and corrupt politicians. Moreover, some perceived that others may attribute climate change to natural causes or believe it to be a hoax.

On average, participants believed that they were doing more than others in their community (i.e., the "better-than-average" effect) on both COVID-19 and climate. As shown in Table 7, this effect was particularly pronounced for COVID-19 behaviors: participants, on average,

Table 6 Respondents' beliefs about why others believe that COVID-19 and climate change are not serious threats

COVID-19

Many people believe that the Coronavirus outbreak Many people believe that climate change is not a serious is not a serious threat. Why do you think this belief threat. Why do you think this belief is prevalent in the is prevalent in the United States today?

Copied and pasted from the web

Nonsensical response

Invisible threat

President does not believe it's serious

Ignorance

It is a serious threat

Low mortality rate

Aversion to restrictions

Politicized

People think it is a conspiracy

Self-centered, apathetic people

US Government does not believe it's serious

Possibility of recovery

Compared to flu

Distrust of governing and scientific authorities, and media

\begin{tabular}{lll}
$20 \%$ & Nonsensical response & $21 \%$ \\
$15 \%$ & Copied and pasted from the web & $20 \%$ \\
$9 \%$ & Invisible, unrecognizable threat & $13 \%$ \\
$9 \%$ & Ignorance & $9 \%$ \\
$8 \%$ & Slow and subtle effects & $7 \%$ \\
$7 \%$ & Propaganda against climate change & $6 \%$ \\
$5 \%$ & Aversion to action & $4 \%$ \\
$4 \%$ & Politicized & $4 \%$ \\
$4 \%$ & Self-centered, apathetic people & $4 \%$ \\
$4 \%$ & President does not believe it's real & $4 \%$ \\
$4 \%$ & It is not a threat & $4 \%$ \\
$3 \%$ & It is a serious threat & $4 \%$ \\
$3 \%$ & Monetary interests & $3 \%$ \\
$3 \%$ & Climate denial & $3 \%$ \\
$3 \%$ & Distrust of governing and scientific authorities, \\
& media and science & $3 \%$ \\
\hline
\end{tabular}


believed that they were doing moderately (as defined by Cohen 1988) more than others on all three COVID-19 behaviors assessed here. Similarly, on climate change, participants, on average, believed that they engaged in moderately more efforts to reduce home energy consumption than others. In contrast, participants, on average, believed that they only engaged in slightly more climate-friendly diet efforts than others and, on average, did not exhibit the better-than-average effect regarding political climate action.

\section{Discussion}

\subsection{Threat perceptions}

Respondents indicated many similarities in threat perceptions of COVID-19 and climate change. Doubting the severity of COVID-19 (e.g., believing that the risk was exaggerated) was highly correlated with similar doubts about climate change, suggesting the possibility that mistrust might reflect a deeper worldview and mistrust of risk communicators. Further, the extent to which participants believed that authoritarian government was needed to address COVID-19 was closely related to a similar perception for climate change, suggesting the possibility that COVID-19 might foster a defensive or authoritarian mindset for some (Stanley et al. 2019) that could extend to other threats. Participants' agreement with statements indicating that lessons from COVID-19 could be applied to climate change suggests that COVID-19 has been a useful "learning experience" for the need to take climate action, at least when individuals were explicitly asked about the connection. Qualitative results also showed that many recognized that both issues would create negative health impacts, although this similarity was not universally recognized as many others described climate change as an "environmental issue" (vs. COVID-19 as a "health issue").

We also found differences in threat perceptions between the two threats. COVID-19 risk perceptions (concern about effects on self and others) were only moderately correlated with climate change risk perceptions. Many also perceived the two threats as unfolding on different timescales: unlike COVID-19, many viewed climate change as a "future problem" (see Miniard et al. 2020; Brügger et al. 2021). These differences suggest that communicating about

Table 7 Differences in self-reported behavior and perception of others' behaviors

\begin{tabular}{|c|c|c|c|c|}
\hline Behavior & $\begin{array}{l}\text { Self-reported } \\
\text { behavior } \\
{[95 \% \mathrm{CI}]}\end{array}$ & $\begin{array}{l}\text { Perceptions of others' behavior [95\% } \\
\text { CI] }\end{array}$ & t-value & $\begin{array}{l}\text { Cohen's } \\
\text { D }\end{array}$ \\
\hline Wear a face mask & $3.16[3.12,3.21]$ & $2.72[2.68,2.77]$ & $16.3 * * *$ & 0.45 \\
\hline Avoid social interaction & $3.11[3.06,3.15]$ & $2.58[2.53,2.62]$ & $18.7 * * *$ & 0.56 \\
\hline $\begin{array}{l}\text { Staying } 6 \mathrm{ft} \text { away from } \\
\text { others }\end{array}$ & $3.19[3.15,3.23]$ & $2.59[2.54,2.63]$ & $21.8 * * *$ & 0.62 \\
\hline Eat climate-friendly diet & $2.27[2.21,2.32]$ & $2.09[2.04,2.14]$ & $7.50 * * *$ & 0.16 \\
\hline Reduce home energy usage & $2.65[2.60,2.69]$ & $2.21[2.16,2.26]$ & $16.8 * * *$ & 0.42 \\
\hline Political climate action & $2.03[1.97,2.10]$ & $2.04[1.98,2.09]$ & $-0.2^{\mathrm{NS}}$ & -0.00 \\
\hline
\end{tabular}

Tests compare means for each self-reported behavior and perceptions of others' behavior. All tests have 1783 degrees of freedom. Responses on 0 "never" to 4 "All the time" scale

${ }^{N S}$ not significant $(\mathrm{p}>.05)$

*** $\mathrm{p}<.001$ 
COVID-19 risks may not necessarily promote awareness of the climate risks. Perhaps communication efforts could focus on explaining connections between these risks in a way that is more salient to lay individuals.

\subsection{Emotional reactions}

Participants indicated both substantive similarities in sources of hope and despair to the two topics. Considering individual and collective action made some participants hopeful about solving both issues. This leads us to an intriguing speculation: if perceptions of individual and collective action are increased on COVID-19, would that also increase hope in finding climate solutions? We also found that perceived apathy and denial made participants feel despair about both topics. Future work should examine whether decreasing perceptions of others' apathy and denial on COVID-19 might also decrease despair on climate change.

In understanding possible links between feelings and climate engagement, some have focused primarily on distinguishing positive from negative feelings (e.g., O'Neill and Nicholson-Cole 2009), while other work suggests that the meaning that individuals ascribe to emotional experiences might be more important than affective valence (Geiger et al. 2021a; Geiger et al. 2021b; also see Chapman et al. 2017) Consistent with the latter perspective, we found that two negative emotions that commonly (although not always) correspond to deeply embedded psychological meaning (i.e., anxiety and despair) predicted greater action intentions on both threats, while boredom, which typically reflects lack of psychological meaning, predicted lesser action intentions on both threats. Yet, not all patterns were similar across the two issues. Two other emotions commonly associated with psychological meaning (anger and hope) predicted greater climate action intentions, but not COVID-19 action intentions. The former could align with van Zomeren et al.' (2019) argument that hope can serve a motivational role in some cases but in other cases simply function to improve mood. Specifically, they argue that hope is likely to be motivational when individuals also perceive that their own action can contribute to a better future. Thus, it is possible that many participants might have been better able to envision how their actions could bring about climate progress than how their actions would address COVID-19. Unexpectedly, exhaustion, which could be associated with a lack of meaning, predicted greater climate action intentions (no relationship with COVID-19 action intentions). Overall, it appears that climate action intentions are more closely related to emotional experiences, and with a more diverse array of emotions, than are COVID-19 action intentions.

\subsection{Normative perceptions}

Extending other work demonstrating that individuals often misperceive others' opinions and behaviors (Geiger and Swim 2016; Lambert et al. 2003; Leviston and Uren 2020; Miller and Prentice 1994), we found preliminary evidence for the "better-than-average" effect across many behaviors with both threats (Leviston and Uren 2020). Interestingly, and counter to expectations, this effect was approximately equally pronounced for both relatively invisible (avoiding social interaction) and visible (wearing a face mask) COVID-19 behaviors. In contrast, the better-than-average effect seemed to vary as expected based on visibility of climate change behaviors: participants exhibited a substantial better-than-average effect regarding perceptions of others' attempts to save energy (largely invisible) but less so for climate-related food choices (somewhat visible), and not at all for political participation (fairly 
visible). Perhaps the novelty of COVID-19 (and the fact that many had less social exposure than usual) led to a greater reliance on media coverage rather than personal experience to assess perceptions of others' behaviors, thus rendering behavioral visibility moot on this topic (see Chia and Lee 2008). Qualitative results add clarity to the reasoning behind perceptions that others lack concern: many believe that politicization, intentional misinformation, threat invisibility, and ignorance explain others' lack of concern regarding both topics.

Although it is possible that these better-than-average perceptions were accurate (i.e., it is possible that MTurk workers may be engaging in more COVID-19 and climate change mitigation behaviors than others in their communities), these findings provide preliminary evidence for public misperceptions regarding other's engagement with many COVID-19 and climate change mitigation behaviors (although not for the publicly visible behavior of political climate action). Future work should consider providing individuals with better insight into others' behaviors and the motives behind them, such as communicating that others use less energy in their homes than many believe (see Schultz et al. 2007), might be useful in promoting action toward these threats.

\section{Limitations and future directions}

Our findings may not generalize to all populations. Although our sample provides substantial heterogeneity for an initial investigation of key questions, it is not fully representative of the US adult population. Future work should also consider crosscultural heterogeneity, as the USA has exhibited high media coverage of the climate denial movement (Painter and Ashe 2012) relative to most other industrialized countries. Additionally, future researchers examining the better-than-average effect may consider asking participants to compare themselves to a group of which the sample is representative (e.g., asking MTurk workers about perceptions of other MTurk workers). Our findings may also be specific to the time of data collection (fairly early in the COVID-19 pandemic). Risk perceptions of COVID-19 might increase as more people know someone who has been severely affected by COVID-19 (Verdery et al. 2020) or as case numbers rise sharply, and decrease as "COVID fatigue" spreads (Godlee 2020) or as case numbers fall sharply and more become vaccinated against the virus. Despite limitations in generalizability, this work provides a useful preliminary picture into responses to these two societal threats.

Future work could examine how contextual information surrounding emotional reactions to threats influences their motivational effects. As Chapman et al. (2017) note, emotions are not "simple levers for behavior change" and rather part of more complex psychological processes. Future work could examine questions such as whether anxiety arising in response to the subjective uncertainty of COVID-19 could promote COVID-mitigation actions, while anxiety arising due to economic insecurity caused by the outbreak (Witteveen and Velthorst 2020) could discourage COVIDmitigation actions. Additionally, longitudinal work could examine emotion-behavior links on different timescales, as it is possible, for example, that despair could promote action in the short term (consistent with our findings) but lead to disengagement over time (as suggested by Hmielowski et al. 2019). 


\section{Conclusion}

As COVID-19 vaccines are mass-distributed in 2021 and onwards, a key question is whether we will aspire to return to "normal" or whether society will learn from the crisis and work to "build back better." Communicators and other social scientists are seeking to understand how the unspeakable social tragedies caused by the COVID-19 pandemic may have also created an opportunity to better engage the public with other societal threats such as climate change (Bouman et al. 2021). Our work represents an initial exploration into identifying learning opportunities from COVID-19 that can be used to more effectively engage people on climate change. We find significant overlaps in threat perceptions, emotional reactions, and normative perceptions across the two issues, although these overlaps are far from universal. We hope that our findings can be used to identify fruitful avenues of communication for public engagement on both topics. As the severity of the climate crisis becomes more apparent, researchers, communicators, and practitioners will need a more diverse toolbox to better engage the public.

Supplementary Information The online version contains supplementary material available at https://doi.org/ 10.1007/s10584-021-03143-8.

Acknowledgements We thank Landon Yoder, Joe Kantenbacher, and Deidra Miniard for research assistance and all our survey participants.

Author contribution NG, AG, and SZA designed the research; SZA collected data; NG, AG, CVS, and SZA analyzed the data; NG, AG, CVS, and SZA wrote the paper.

Funding This work is supported by NSF grant SES-1658804 from Decision, Risk and Management Sciences and by the Environmental Resilience Institute, funded by Indiana University's Prepared for Environmental Change Grand Challenge initiative.

Data availability Data and $\mathrm{R}$ code is publicly available at https://osf.io/qhgsm/.

\section{Declarations}

Ethics approval All research was approved by the Institutional Review Board at Indiana University. This article does not contain any studies with animals. All procedures performed in studies involving human participants were in accordance with the ethical standards of the institutional research committee and with the 1964 Helsinki declaration and its later amendments.

Consent to participate All survey respondents provided implied consent.

Consent for publication All authors gave consent for publication.

Conflict of interest The authors declare no competing interests. 


\section{References}

Ajzen I (1991) The theory of planned behavior. Organ Behav Hum Decis Process 50(2):179-211. https://doi.org/ 10.1016/0749-5978(91)90020-T

Albrecht G (2011) Chronic environmental change: emerging 'psychoterratic' syndromes. In: Weissbecker I (ed) Climate Change and Human Well-Being: Global Challenges and Opportunities. Springer, New York, pp 43-56. https://doi.org/10.1007/978-1-4419-9742-5_3

Attari SZ (2021) Transforming energy use. Curr Opin Behav Sci 42:104-108

Attari SZ, Krantz DH, Weber EU (2014) Reasons for cooperation and defection in real-world social dilemmas. Judgm Decis Mak 9(6)

Balmford A, Fisher B, Mace GM, Wilcove DS, Balmford B (2020) Analogies and lessons from COVID-19 for tackling the extinction and climate crises. Curr Biol 30(17):R969-R971. https://doi.org/10.1016/j.cub.2020. 06.084

Bergquist P, Mildenberger M, Stokes L (2020) Combining climate, economic, and social policy builds public support for climate action in the US. Environ Res Lett. https://doi.org/10.1088/1748-9326/ab81c1

Bouman T, Steg L, Dietz T (2021) Insights from early COVID-19 responses about promoting sustainable action. Nature Sustainability 4(3):194-200 10/ghp66b

Brosch T (2021) Affect and emotions as drivers of climate change perception and action: a review. Curr Opin Behav Sci 42:15-21. https://doi.org/10.1016/j.cobeha.2021.02.001

Brügger A, Tobias R, Monge-Rodríguez FS (2021) Public perceptions of climate change in the Peruvian Andes. Sustainability 13(5):2677 10/gh65px

Bury SM, Wenzel M, Woodyatt L (2019) Against the odds: hope as an antecedent of support for climate change action. Br J Soc Psychol:e12343. https://doi.org/10.1111/bjso.12343

Chapman DA, Lickel B, Markowitz EM (2017) Reassessing emotion in climate change communication. Nat Clim Chang 7(12):850

Chia SC, Lee W (2008) Pluralistic ignorance about sex: The direct and the indirect effects of media consumption on college students' misperception of sex-related peer norms. International Journal of Public Opinion Research 20(1):52-73

Cialdini RB, Goldstein NJ (2004) Social influence: Compliance and conformity. Annu Rev Psychol 55(1):591621. https://doi.org/10.1146/annurev.psych.55.090902.142015

Clayton S, Manning C, Krygsman K, \& Speiser M (2017). Mental health and our changing climate: impacts, implications, and guidance (p. 70). American Psychological Association, and ecoAmerica

Clinton J, Cohen J, Lapinski J, Trussler M (2021) Partisan pandemic: how partisanship and public health concerns affect individuals' social mobility during COVID-19. Sci Adv 7(2):eabd7204 10/gjjbbk

Cohen J (1988). Statistical Power analysis for the behavioral sciences (2nd.). Erlbaum

Copeland WE, Gaydosh L, Hill SN, Godwin J, Harris KM, Costello EJ, Shanahan L (2020) Associations of despair with suicidality and substance misuse among young adults. JAMA Netw Open 3(6):e208627. https:// doi.org/10.1001/jamanetworkopen.2020.8627

Czeisler MÉ, Tynan MA, Howard ME, Honeycutt S, Fulmer EB, Kidder D, Robbins R, Barger L, Facer-Childs ER, Baldwin G, Rajaratnam SMW, Czeisler CA (2020) Public Attitudes, behaviors, and beliefs related to COVID-19, stay-at-home orders, nonessential business closures, and public health guidance - United States, New York City, and Los Angeles, May 5-12, 2020. MMWR Morb Mortal Wkly Rep 69:751-758 10/ gg5j7w

Dillard JP, Peck E (2000) Affect and persuasion: emotional responses to public service announcements. Commun Res 27(4):461-495. https://doi.org/10.1177/009365000027004003

Doherty KL, Webler TN (2016) Social norms and efficacy beliefs drive the alarmed segment's public-sphere climate actions. Nat Clim Chang. https://doi.org/10.1038/nclimate3025

Feldman L, Hart PS (2016) Using political efficacy messages to increase climate activism: the mediating role of emotions. Sci Commun 38(1):99-127 10/gft2m6

Geiger N, Swim JK (2016) Climate of silence: Pluralistic ignorance as a barrier to climate change discussion. J Environ Psychol 47:79-90. https://doi.org/10.1016/j.jenvp.2016.05.002

Geiger N, McLaughlin B, Velez J (2021a) Not all boomers: temporal orientation explains inter- and intra-cultural variability in the link between age and climate engagement. Clim Chang 166(1):12. https://doi.org/10.1007/ s10584-021-03116-X

Geiger N, Swim JK, Gasper K, Fraser J, \& Flinner K (2021b). How do I feel when I think about taking action? Hope and boredom, not anxiety and helplessness, predict intentions to take climate action. Under review

Godlee F (2020). Covid-19: surviving the long road ahead. BMJ, 369. 10/ghmshg

Goldberg MH, van der Linden S, Leiserowitz A, Maibach E (2020) Perceived social consensus can reduce ideological biases on climate change. Environ Behav 52(5):495-517 10/gg4359 
Gordon M, Lumley T, \& Gordon MM (2019). Package 'forestplot.' Disponével Em: Https://Cran. Rproject. Org/ Web/Packages/Forestplot/Forestplot. Pdf. Acesso Em, 31

Hlavac M (2018) Stargazer: Well-Formatted Regression and Summary Statistics Tables. R package version 5(2): 2 https://CRAN.R-project.org/package=stargazer

Hmielowski JD, Donaway R, Wang MY (2019) Environmental Risk information seeking: the differential roles of anxiety and hopelessness. Environ Commun 13(7):894-908. https://doi.org/10.1080/17524032.2018. 1500926

Hornsey MJ, Fielding KS (2016) A cautionary note about messages of hope: focusing on progress in reducing carbon emissions weakens mitigation motivation. Glob Environ Chang 39:26-34. https://doi.org/10.1016/j. gloenvcha.2016.04.003

Howarth C, Bryant P, Corner A, Fankhauser S, Gouldson A, Whitmarsh L, Willis R (2020) Building a social mandate for climate action: lessons from COVID-19. Environ Resour Econ 76(4):1107-1115. https://oi. org/10.1007/s10640-020-00446-9

IPCC. (2019). Global Warming of $1.5^{\circ} \mathrm{C}$. An IPCC Special Report on the impacts of global warming of $1.5^{\circ} \mathrm{C}$ above pre-industrial levels and related global greenhouse gas emission pathways, in the context of strengthening the global response to the threat of climate change, sustainable development, and efforts to eradicate poverty. https://www.ipcc.ch/sr15/

Jetten J, Haslam SA, Reicher S, Cruwys, T. (Eds.). (2020) Together apart: the psychology of covid-19, 1st edn. SAGE Publications

Johns Hopkins COVID-19 Map. (2021). Johns Hopkins Coronavirus Resource Center. https://coronavirus.jhu. edu/map.html

Jones CA, Davison A (2021) Disempowering emotions: the role of educational experiences in social responses to climate change. Geoforum 118:190-200 10/gjcmrd

Kim HK, Niederdeppe J (2013) The role of emotional response during an H1N1 influenza pandemic on a College campus. J Public Relat Res 25(1):30-50. https://doi.org/10.1080/1062726X.2013.739100

Kleres J, \& Wettergren $\AA$ (2017). Fear, hope, anger, and guilt in climate activism. Social Movement Studies, 15

Kuzemko C, Bradshaw M, Bridge G, Goldthau A, Jewell J, Overland I, Scholten D, Van de Graaf T, Westphal K (2020) Covid-19 and the politics of sustainable energy transitions. Energy Res Soc Sci 68:101685. https:// doi.org/10.1016/j.erss.2020.101685

Lambert TA, Kahn AS, Apple KJ (2003) Pluralistic ignorance and hooking up. J Sex Res 40(2):129-133 10/ dmghkw

Landry N, Gifford R, Milfont TL, Weeks A, Arnocky S (2018) Learned helplessness moderates the relationship between environmental concern and behavior. J Environ Psychol 55:18-22 10/gdbfbm

Lazarus RS (1999) Hope: An emotion and a vital coping resource against despair. Soc Res 66(2):653-678

Leiserowitz A, Maibach E, Rosenthal S, Kotcher J, Bergquist P, Ballew MT, Goldberg M, Gustafson A, \& Wang X (2020). Climate change in the American mind: April 2020. 10/ghk7tg

Leviston Z, Uren HV (2020) Overestimating one's "green" behavior: better-than-average bias may function to reduce perceived personal threat from climate change. J Soc Issues 76(1):70-85 10/gjcmtp

Leviston Z, Walker I, Morwinski S (2013) Your opinion on climate change might not be as common as you think. Nat Clim Chang 3(4):334-337. https://doi.org/10.1038/nclimate1743

Loewenstein GF, Weber EU, Hsee CK, Welch N (2001) Risk as feelings. Psychol Bull 127(2):267 10/fgmsnf

Lu H, Schuldt JP (2015) Exploring the role of incidental emotions in support for climate change policy. Clim Chang 131(4):719-726. https://doi.org/10.1007/s10584-015-1443-x

Maibach E, Miller J, Armstrong F, El Omrani O, Zhang Y, Philpott N, Atkinson S, Rudoph L, Karliner J, Wang J (2021) Health professionals, the Paris agreement, and the fierce urgency of now. The Journal of Climate Change and Health 1:100002

Manzanedo RD, Manning P (2020) COVID-19: Lessons for the climate change emergency. Sci Total Environ 742:140563 10/ghbvhd

Markowitz EM, Slovic P, Västfjäll D, Hodges SD (2013) Compassion fade and the challenge of environmental conservation. Judgm Decis Mak 8(4):397-406

McCright AM, Dunlap RE (2011) The politicization of climate change and polarization in the American public's views of global warming, 2001-2010. Sociol Q 52(2):155-194. https://doi.org/10.1111/j.1533-8525.2011. 01198.x

Mildenberger M, Tingley D (2017) Beliefs about climate beliefs: the importance of second-order opinions for climate politics. Br J Polit Sci:1-29

Miller DT, Prentice DA (1994) Collective errors and errors about the collective. Personal Soc Psychol Bull 20(5): 541-550 10/fnmbzk

Miniard D, Kantenbacher J, Attari SZ (2020) Shared vision for a decarbonized future energy system in the United States. Proc Natl Acad Sci 117(13):7108-7114 10/ggw88v 
Moser SC (2007) More bad news: The risk of neglecting emotional responses to climate change information. In: Dilling L, Moser SC (eds) Creating a climate for change: communicating climate change and facilitating social change. Cambridge University Press, Cambridge Core, pp 64-80. https://doi.org/10.1017/ CBO9780511535871.006

Nabi RL (2015) Emotional flow in persuasive health messages. Health Commun 30(2):114-124. https://doi.org/ $10.1080 / 10410236.2014 .974129$

Norgaard KM (2011). Living in Denial: climate change, emotions, and everyday life. MIT Press

O'Neill S, Nicholson-Cole S (2009) "Fear won't do it": promoting positive engagement with climate change through visual and iconic representations. Sci Commun 30(3):355-379. https://doi.org/10.1177/ 1075547008329201

Ojala M (2012) Hope and climate change: the importance of hope for environmental engagement among young people. Environ Educ Res 18(5):625-642. https://doi.org/10.1080/13504622.2011.637157

Oreskes N, Conway EM (2011) Merchants of doubt: how a handful of scientists obscured the truth on issues from tobacco smoke to global warming. Bloomsbury Press

Painter J, Ashe T (2012) Cross-national comparison of the presence of climate scepticism in the print media in six countries, 2007-10. Environ Res Lett 7(4):044005. https://doi.org/10.1088/1748-9326/7/4/044005

Pyszczynski, T., Solomon, S., \& Greenberg, J. (2003). In the wake of 9/11: the psychology of terror (pp. xiv, 227). American Psychological Association. https://doi.org/10.1037/10478-000

Qian M, Ye D, Zhong J, Xu K, Zhang L, Huang Z, Dong W, Liu X, Zhang X, Zhang Z, Wang C, Nie J (2005) Behavioural, cognitive and emotional responses to SARS: differences between college students in Beijing and Suzhou. Stress Health 21(2):87-98. https://doi.org/10.1002/smi.1043

R Core Team. (2020). R: A language and environment for statistical computing.

Rigaud KK, Jones B, Bergmann J, Clement V, Ober K, Schewe J, Adamo S, McCusker B, Heuser S, Midgley A (2018) Groundswell: preparing for internal climate migration. World Bank, Washington, DC

Roeser S (2012) Risk Communication, public engagement, and climate change: a role for emotions. Risk Anal 32(6):1033-1040 10/bttk

Salomon E, Preston J, Tannenbaum MB (2017) Climate change helplessness and the (de)moralization of individual energy behavior. J Exp Psychol Appl 23:15-28. https://doi.org/10.1037/xap0000105

Schultz PW, Nolan JM, Cialdini RB, Goldstein NJ, Griskevicius V (2007) The constructive, destructive, and reconstructive power of social norms. Psychol Sci 18(5):429-434. https://doi.org/10.1111/j.1467-9280. 2007.01917.x

Singleton J (2010). Head, heart and hands model for transformative learning: place as context for changing sustainability values. Education, 2010. http://www.jsedimensions.org/wordpress/content/head-heart-andhands-model-for-transformative-learning-place-as-context-for-changing-sustainability-values_2015_03/

Slovic P (1987) Perception of risk. Science 236(4799):280-285. https://doi.org/10.1126/science.3563507

Slovic P, Peters E (2006) Risk perception and affect. Curr Dir Psychol Sci 15(6):322-325. https://doi.org/10. 1111/j.1467-8721.2006.00461.x

Smith N, Leiserowitz A (2014) The role of emotion in global warming policy support and opposition. Risk Anal 34(5):937-948. https://doi.org/10.1111/risa.12140

Stanley SK, Milfont TL, Wilson MS, Sibley CG (2019) The influence of social dominance orientation and rightwing authoritarianism on environmentalism: a five-year cross-lagged analysis. PLoS One 14(7):e0219067 $10 / \operatorname{gg} 3342$

Stanley SK, Hogg TL, Leviston Z, Walker I (2021) From anger to action: differential impacts of eco-anxiety, eco-depression, and eco-anger on climate action and wellbeing. The Journal of Climate Change and Health 1:100003. https://doi.org/10.1016/j.joclim.2021.100003

Swim JK, Geiger N (2017) From alarmed to dismissive of climate change: a single item assessment of individual differences in concern and issue involvement. Environ Commun 11(4):568-586. https://doi.org/10.1080/ 17524032.2017.1308409

Swim JK, Geiger N, Lengieza ML (2019) Climate change marches as motivators for bystander collective action. Frontiers in Communication 4:4 10/gfxfbw

Tannenbaum MB, Hepler J, Zimmerman RS, Saul L, Jacobs S, Wilson K, Albarracin D (2015) Appealing to fear: a meta-analysis of fear appeal effectiveness and theories. Psychol Bull 141(6):1178-1204 10/f7wvhw

Taylor S (2020) Anxiety disorders, climate change, and the challenges ahead: introduction to the special issue. J Anxiety Disord 76:102313. https://doi.org/10.1016/j.janxdis.2020.102313

US Census Bureau. (2019). American FactFinder. https://factfinder.census.gov/

Van Doorn J, Zeelenberg M, Breugelmans SM (2014) Anger and prosocial behavior. Emot Rev 6(3):261-268 10/ggqsh9

van Zomeren M, Spears R, Leach CW (2010) Experimental evidence for a dual pathway model analysis of coping with the climate crisis. J Environ Psychol 30(4):339-346. https://doi.org/10.1016/j.jenvp.2010.02. 006 
van Zomeren M, Pauls IL, Cohen-Chen S (2019) Is hope good for motivating collective action in the context of climate change? Differentiating hope's emotion-and problem-focused coping functions. Glob Environ Chang 58:101915 10/ggbkc9

Verdery AM, Smith-Greenaway E, Margolis R, Daw J (2020) Tracking the reach of COVID-19 kin loss with a bereavement multiplier applied to the United States. Proc Natl Acad Sci 117(30):17695-17701 10/gg4rmf

Wang C, Pan R, Wan X, Tan Y, Xu L, Ho CS, Ho RC (2020) Immediate Psychological responses and associated factors during the initial stage of the 2019 coronavirus disease (COVID-19) epidemic among the general population in China. Int J Environ Res Public Health 17(5):1729. https://doi.org/10.3390/ijerph17051729

Westgate EC, Wilson TD (2018) Boring thoughts and bored minds: the MAC model of boredom and cognitive engagement. Psychol Rev 125(5):689 10/gffhgc

Wickham H, Chang W, Wickham MH (2016) Package 'ggplot2.' Create Elegant Data Visualisations Using the Grammar of Graphics. Version 2(1):1-189

Widmann T (2020). Fear, Hope, and COVID-19: Strategic emotional rhetoric in political communication and its impact on the mass public (SSRN Scholarly Paper ID 3679484; Issue ID 3679484). Social Science Research Network. https://doi.org/10.2139/ssrn.3679484

Witteveen D, Velthorst E (2020) Economic hardship and mental health complaints during COVID-19. Proc Natl Acad Sci 117(44):27277-27284 10/ghjwf3

Yoon M-K, Kim S-Y, Ko H-S, Lee M-S (2016) System effectiveness of detection, brief intervention and refer to treatment for the people with post-traumatic emotional distress by MERS: a case report of community-based proactive intervention in South Korea. Int J Ment Heal Syst 10(1):51. https://doi.org/10.1186/s13033-0160083-5

Publisher's note Springer Nature remains neutral with regard to jurisdictional claims in published maps and institutional affiliations. 